in vivo $34: 2991-2996(2020)$

doi:10.21873/invivo.12130

\title{
Stereotactic Body Radiotherapy for Pulmonary Oligometastasis from Colorectal Cancer
}

\author{
NAO KOBAYASHI ${ }^{1,2}$, TAKANORI ABE ${ }^{1}$, SHIN-EI NODA $^{1}$, YU KUMAZAKI ${ }^{1}$, RYUTA HIRAI $^{1}$, \\ MITSUNOBU IGARI ${ }^{1}$, TOMOMI AOSHIKA ${ }^{1}$, SATOSHI SAITO ${ }^{1}$, YASUHIRO RYUNO ${ }^{1}$ and SHINGO KATO ${ }^{1}$ \\ ${ }^{1}$ Department of Radiation Oncology, Saitama Medical University, International Medical Center, Saitama, Japan; \\ ${ }^{2}$ Department of Radiation Oncology, Gunma University Hospital, Gunma, Japan
}

\begin{abstract}
Background/Aim: A retrospective study was conducted to evaluate the safety and efficacy of stereotactic body radiotherapy (SBRT) for pulmonary oligometastasis from colorectal cancer (CRC). Patients and Methods: Patients with pulmonary oligometastasis from CRC who were treated with SBRT between April 2010 and October 2018 were enrolled in this study. All patients underwent SBRT using Cyberknife ${ }^{\circledR}$ with a dose of 54-60 Gy in 3 fractions to $99 \%$ of the clinical target volume. The treatment efficacy was evaluated by the local control (LC) and overall survival (OS) rates. The toxicity was evaluated using the National Cancer Institute's Common Terminology Criteria for Adverse Events version 4.0. Results: Twenty-six lesions in 20 patients were treated with SBRT. The median followup duration was 19 months (range=6-98 months). Local recurrence occurred in 6 of 26 lesions with a median followup of 12 months. The 2-year LC and OS rates were $65.8 \%$ and $88.6 \%$, respectively. No patient developed $\geq$ grade 2 toxicity in the lung and other sites. Conclusion: Although very high doses were delivered to the tumors with SBRT, the LC of pulmonary metastasis from CRC was not satisfactory when compared to that for stage I primary non-small cell lung cancer reported in the literature.
\end{abstract}

Colorectal cancer (CRC) is one of the most common malignant tumors and the fourth cause of cancer-related deaths worldwide (1). Approximately $20 \%$ of patients with stage IV disease present with distant metastasis at the time

This article is freely accessible online.

Correspondence to: Shingo Kato, MD, Department of Radiation Oncology, Saitama Medical University, International Medical Center, 1397-1 Yamane, Hidaka, Saitama 350-1298, Japan. Tel: +81 429844136, Fax: +81 429844136, e-mail: s_kato@saitamamed.ac.jp

Key Words: Stereotactic body radiotherapy (SBRT), oligorecurrence, pulmonary oligometastasis, colorectal cancer (CRC). of diagnosis (2). Moreover, approximately $20 \%$ of patients who receive surgery for their primary tumor develop distant metastasis (3). Patients with distant metastasis are generally considered candidates of systemic chemotherapy. However, some cases of oligometastasis/oligorecurrence, which are at stages of limited-spread disease, may be curable with local therapy such as surgery or radiation therapy $(4,5)$. Surgical resection is considered the gold standard for resectable pulmonary oligometastasis of CRC (6). However, the invasiveness of pulmonary surgery is not insignificant, and may be infeasible for older patients, those with poor pulmonary or cardiac function, and those who have previous history of pulmonary surgery (7). Therefore, indications of surgery should be carefully determined.

Stereotactic body radiotherapy (SBRT) can deliver a very high radiation dose to the tumor while minimizing the dosage to the surrounding normal tissues, which results in high local tumor control rate with acceptable normal tissue toxicity (8). Several studies have reported on the efficacy of SBRT for early-stage lung cancer $(9,10)$, and this treatment has become one of the standard treatments for the disease (6). Several others have reported on the use of SBRT for pulmonary oligometastasis $(5,7,11)$. However, the safety and efficacy of SBRT for pulmonary oligometastasis has not been thoroughly evaluated and its indication has not been determined yet (7).

We treated patients with pulmonary oligometastasis from CRC using SBRT, if they were deemed to be medically inoperable or if they had refused surgery. We conducted a retrospective study to evaluate the safety and efficacy of SBRT for the disease.

\section{Patients and Methods}

Patients. Patients with pulmonary oligometastasis from CRC who were treated with SBRT at our institute between April 2010 and October 2018 were enrolled in this study. Inclusion criteria were as follows: (i) no evidence of recurrence at the primary site, (ii) absent or controlled extrathoracic disease, (iii) $\leq 3$ synchronous lung metastases at the time of treatment, (iv) maximum tumor 
diameter $\leq 30 \mathrm{~mm}$, (v) patients deemed medically unsuitable for surgery or had refused surgery, (vi) Eastern Cooperative Oncology Group (ECOG) performance status (PS) 0-1, (vii) complete lack of serious cardiopulmonary dysfunction, active interstitial pneumonia, or connective tissue diseases. Patients with a previous history of systemic chemotherapy and/or surgery and/or SBRT for pulmonary metastasis were included in the study. This study was approved by the institutional review board of our institute (Registration number: 19-281).

Treatment. Patients underwent a 4-dimensional (4D) computed tomography (CT) scan of the chest with a slice thickness of $2.5 \mathrm{~mm}$ to evaluate the respiratory motion of the tumor. When the tumor respiratory motion was more than $10 \mathrm{~mm}, 2$ or 3 fiducial markers (Gold Marker ${ }^{\circledR}$; Olympus Co., Tokyo, Japan) were placed near the tumor using a bronchoscope.

Gross tumor volume (GTV) was defined as the visible tumor in the lung window on the treatment planning CT images. Clinical target volume (CTV) was defined as the same volume as the GTV. The maximum intensity projection was reconstructed from the $4 \mathrm{D}$ CT images and was used to delineate the internal target volume (ITV) from the CTV. The planning target volume (PTV) was determined by adding a 2-mm safety margin in all directions to the ITV. The organs at risk (OARs), including the brachial plexus, trachea and bronchus, esophagus, heart and great vessels, lung fields, ribs, and spinal cord, were contoured on the planning CT images using the soft-tissue window.

Patients were treated with SBRT using Cyberknife ${ }^{\circledR}$ (Accuray; Sunnyvale, CA, USA) technology with 6-MV x-rays. When the tumor respiratory motion was more than $10 \mathrm{~mm}$, we adopted "Synchrony respiratory tracking," which allows the radiation beam to be moved along with the movement of the lung tumor moving synchronously with the markers. When the tumor respiratory motion was less than $10 \mathrm{~mm}$, we adopted "Xsight spine tracking," which allows the position of the tumor to be assessed and corrected based on its relative location to the spine.

Treatment plans were calculated using a Ray Tracing algorithm created before 2015 and a Monte Carlo algorithm created after 2015. In general, the prescribed dose was 54 or 60 Gy in 3 fractions to $99 \%$ of the CTV, but we considered it acceptable to alter the dose and fractionation according to the dose constraints of the OARs $(12,13)$.

Follow-up. Follow-up with patients was conducted every 1-6 months for the first 2 years and every 3-6 months thereafter. To evaluate disease status and pulmonary toxicity, all patients underwent examinations consisting of physical exam, blood tests [including serum carcinoembryonic antigen (CEA) and carbohydrate antigen 19-9 (CA19-9)], and CT scans from the chest to the pelvis. Pulmonary toxicity was graded using the National Cancer Institute's Common Terminology Criteria for Adverse Events (CTCAE), version 4.0. No local recurrence was defined as being free from tumor recurrence inside the originally irradiated area. When a tumor was found in the lung outside the irradiated area, it was considered to be a new tumor.

Statistical analysis. Local control (LC) duration was measured from the date of SBRT initiation to the date of local recurrence. Overall survival (OS) duration was measured from the date of SBRT initiation to the date of death or the most recent follow-up. The rates of LC and OS were calculated using the Kaplan-Meier method.
Univariate analyses were performed to determine significant prognostic factors associated with LC, and the differences were evaluated using the log-rank test. Statistical significance was defined as a $p$-value of $<0.05$. SPSS software version 25.0 (IBM, NY, USA) was used for statistical analysis.

\section{Results}

Patient and tumor characteristics. Twenty-six lesions in 20 patients were analyzed in the present study. Five patients had colon cancer and 15 had rectal cancer. All patients underwent definitive surgery for their primary tumors. Three patients had stage IV disease with a solitary pulmonary or liver metastasis, and 17 patients developed pulmonary metastasis 7 to 77 months after surgery. Ten patients received chemotherapy before SBRT, depending on the clinical or pathological stage. Regarding pulmonary metastasis, 14 patients had 1 tumor, 5 had 2 tumors, and 1 had 3 tumors. The median size of the pulmonary tumor was $7 \mathrm{~mm}$ (range $=5-16 \mathrm{~mm}$ ). Patient and tumor characteristics are summarized in Table I.

Local control and disease progression. The median followup period after SBRT was 19 months (range=6-98 months). Local recurrence occurred in 6 of 26 lesions (23\%). Median time to local recurrence was 12 months (range $=7-14$ months). Three of the 6 recurrent tumors were surgically salvaged and 1 patient received adjuvant chemotherapy after salvage surgery.

Thirteen patients developed distant metastasis outside the irradiated lung area and/or outside the lung, and 3 patients died of recurrent CRC. The 2-year rates of LC and OS were $65.8 \%(95 \% \mathrm{CI}=65.4-66.7)$ and $88.6 \%(95 \% \mathrm{CI}=87.9-89.6)$, respectively (Figures 1 and 2).

Toxicity. Grade 1 radiation pneumonitis was observed in 22 cases $(84.6 \%) 2$ to 9 months (median, 4.5 months) after SBRT. No patient developed $\geq$ grade 2 pulmonary toxicity. None of our patients developed other $\geq$ grade 2 late adverse events during the follow-up duration.

Prognostic factors. The relationships between several patient and tumor characteristics and treatment factors of SBRT are presented in Table II. In the univariate analysis, tumor size was the only significant prognostic factor for LC, and the LC of the patients with tumor size $\geq 10 \mathrm{~mm}$ was significantly poorer than that of those with tumor size $<10 \mathrm{~mm}(p=0.022)$.

\section{Discussion}

The importance of surgery and SBRT for pulmonary oligometastasis from CRC has recently become increasingly evident. While surgery remains the gold standard for resectable oligometastasis from $\mathrm{CRC}$, local control outcomes 
Table I. Characteristics of patients and tumors.

\begin{tabular}{|c|c|c|}
\hline Variables & $\begin{array}{c}\text { No. of patients } \\
(\%)\end{array}$ & $\begin{array}{c}\text { No. of lesions } \\
(\%)\end{array}$ \\
\hline \multicolumn{3}{|l|}{ Age (years) } \\
\hline Median & 69 & \\
\hline Range & $40-88$ & \\
\hline \multicolumn{3}{|l|}{ Gender } \\
\hline Male & $13(65 \%)$ & \\
\hline Female & $7(35 \%)$ & \\
\hline \multicolumn{3}{|l|}{ ECOG PS } \\
\hline 0 & $15(75 \%)$ & \\
\hline 1 & $5(25 \%)$ & \\
\hline \multicolumn{3}{|l|}{ Primary tumor site } \\
\hline Colon & $5(25 \%)$ & \\
\hline Rectum & $15(75 \%)$ & \\
\hline \multicolumn{3}{|c|}{ Histological type of the primary tumor } \\
\hline Well & $6(30 \%)$ & \\
\hline Mod & $11(55 \%)$ & \\
\hline Unknown & $3(15 \%)$ & \\
\hline \multicolumn{3}{|l|}{$\mathrm{T}$ stage of the primary tumor } \\
\hline 1 & $3(15 \%)$ & \\
\hline 2 & $1(5 \%)$ & \\
\hline 3 & $9(45 \%)$ & \\
\hline 4 & $7(35 \%)$ & \\
\hline \multicolumn{3}{|l|}{$\mathrm{N}$ stage of the primary tumor } \\
\hline 0 & $9(45 \%)$ & \\
\hline 1 & $4(20 \%)$ & \\
\hline 2 & $7(35 \%)$ & \\
\hline \multicolumn{3}{|l|}{ M stage of the primary tumor } \\
\hline 0 & $17(85 \%)$ & \\
\hline 1 & $3(15 \%)$ & \\
\hline \multicolumn{3}{|l|}{ Timing of SBRT } \\
\hline Synchronous & & $0(0 \%)$ \\
\hline $1^{\text {st }}$ recurrence & & $15(58 \%)$ \\
\hline $2^{\text {nd }}$ recurrence or more & & $11(42 \%)$ \\
\hline \multicolumn{3}{|l|}{ No. of pulmonary tumors } \\
\hline 1 & $14(70 \%)$ & \\
\hline 2 & $5(25 \%)$ & \\
\hline 3 & $1(5 \%)$ & \\
\hline \multicolumn{3}{|c|}{ CEA level $(\mathrm{ng} / \mathrm{ml})$ within 6 mo of SBRT } \\
\hline$<5$ & & $5(19 \%)$ \\
\hline$\geq 5$ & & $18(69 \%)$ \\
\hline Unknown & & $3(12 \%)$ \\
\hline \multicolumn{3}{|c|}{ CA19-9 level (U/ml) within $6 \mathrm{mo}$ of SBRT } \\
\hline$<37.0$ & & $22(85 \%)$ \\
\hline$\geq 37.0$ & & $0(0 \%)$ \\
\hline Unknown & & $4(15 \%)$ \\
\hline \multicolumn{3}{|l|}{ Previous chemotherapy before SBRT } \\
\hline Yes & $10(50 \%)$ & $13(50 \%)$ \\
\hline No & $10(50 \%)$ & $13(50 \%)$ \\
\hline \multicolumn{3}{|l|}{ GTV (mm) } \\
\hline Median & & 7 \\
\hline Range & & $5-16$ \\
\hline \multicolumn{3}{|l|}{ Prescription dose } \\
\hline $60 \mathrm{~Gy} / 3 \mathrm{fx}(\mathrm{BED} 10=180 \mathrm{~Gy})$ & & $6(23 \%)$ \\
\hline $54 \mathrm{~Gy} / 3 \mathrm{fx}(\mathrm{BED} 10=151.2 \mathrm{~Gy})$ & & $17(65 \%)$ \\
\hline Other & & $3(12 \%)$ \\
\hline \multicolumn{3}{|l|}{ Adjuvant chemotherapy after SBRT } \\
\hline Yes & $3(15 \%)$ & $3(12 \%)$ \\
\hline No & $15(75 \%)$ & $21(81 \%)$ \\
\hline Unknown & $2(10 \%)$ & $2(8 \%)$ \\
\hline
\end{tabular}

ECOG: Eastern Cooperative Oncology Group; well: well differentiated adenocarcinoma; mod: moderately differentiated adenocarcinoma; SBRT: stereotactic body radiotherapy; CEA: carcinoembryonic antigen, CA19-9: carbohydrate antigen 19-9; GTV: gross tumor volume; fx: fractions; BED: biologically effective dose.

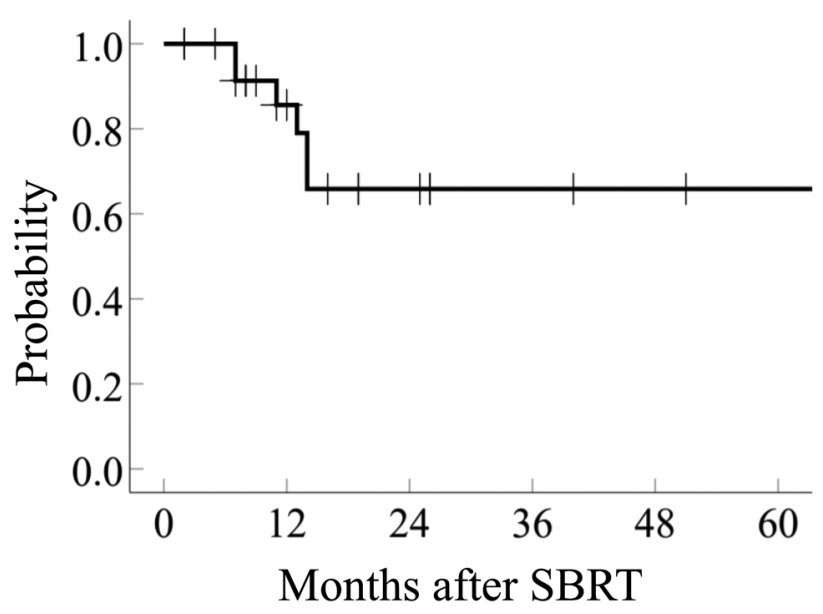

Figure 1. Local control of pulmonary oligometastasis from colorectal cancer treated with stereotactic body radiotherapy (SBRT).

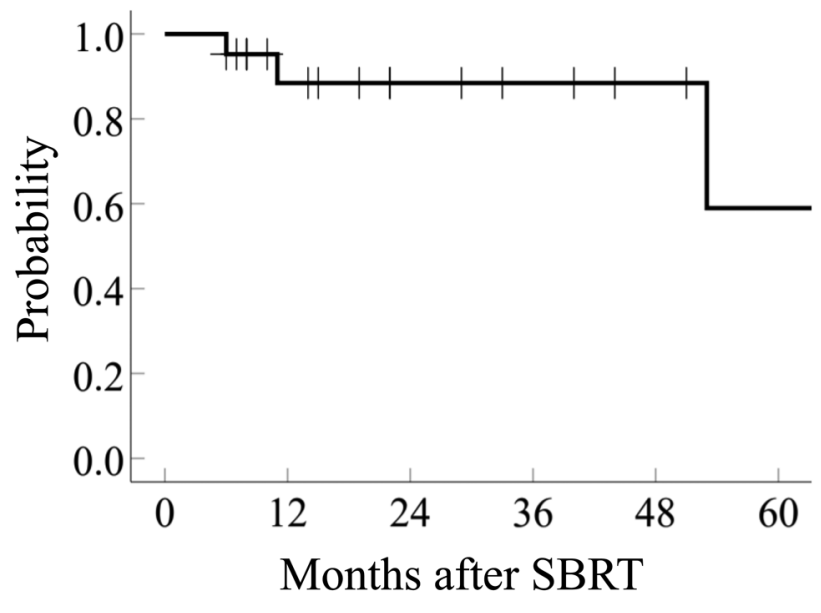

Figure 2. Overall survival of patients with pulmonary oligometastasis from colorectal cancer treated with stereotactic body radiotherapy (SBRT).

in recent reports of SBRT have closely approached those of surgery. Several investigators have reported 2-year LC and OS rates of $53 \%$ to $100 \%$ and $68 \%$ to $92 \%$, respectively, in their SBRT series (14-19), which were almost comparable to those of surgery $(20,21)$. In the present study, we treated patients with SBRT using the Cyberknife ${ }^{\circledR}$ system, and report 2-year rates of $65.8 \%$ and $88.6 \%$ for LC and OS, respectively. Therefore, the results of the present study were considered comparable to those of previous reports.

However, the LC rates following SBRT for pulmonary metastases from CRC seemed unsatisfactory when compared to those for stage I non-small cell lung cancer or for pulmonary metastases from other cancers, which 
Table II. Prognostic factors for local control.

\begin{tabular}{|c|c|c|c|}
\hline & $\mathrm{n}$ & $\begin{array}{c}\text { 2-year LC } \\
\text { rate }(\%)\end{array}$ & $p$-Value \\
\hline Gender & & & 0.769 \\
\hline Male & 18 & 72.2 & \\
\hline Female & 8 & 87.5 & \\
\hline Primary lesion & & & 0.975 \\
\hline Colon & 7 & 71.4 & \\
\hline Rectum & 19 & 78.9 & \\
\hline T stage & & & 0.655 \\
\hline $\mathrm{T} 1, \mathrm{~T} 2$ & 5 & 100.0 & \\
\hline $\mathrm{T} 3, \mathrm{~T} 4$ & 21 & 71.4 & \\
\hline \multicolumn{4}{|l|}{$\mathrm{N}$ stage } \\
\hline 0.559 & & & \\
\hline No & 11 & 90.9 & \\
\hline $\mathrm{N} 1, \mathrm{~N} 2$ & 15 & 66.7 & \\
\hline CEA before SBRT & & & 0.878 \\
\hline$<5$ & 19 & 84.2 & \\
\hline$\geq 5$ & 4 & 75.0 & \\
\hline Unknown & 3 & & \\
\hline CA19-9 before SBRT & & & 0.156 \\
\hline$<20$ & 15 & 86.7 & \\
\hline$\geq 20$ & 7 & 71.4 & \\
\hline Unknown & 4 & & \\
\hline No. of lung metastases & & & 0.055 \\
\hline$<2$ & 16 & 87.5 & \\
\hline$\geq 2$ & 10 & 60.0 & \\
\hline Diameter of lung metastases (mm) & & & 0.022 \\
\hline$<10$ & 18 & 88.9 & \\
\hline$\geq 10$ & 8 & 50.0 & \\
\hline BED10 & & & 0.534 \\
\hline$<150$ & 3 & 66.7 & \\
\hline$\geq 150$ & 23 & 78.3 & \\
\hline Adjuvant chemotherapy after SBRT & & & 0.402 \\
\hline Yes & 3 & 33.3 & \\
\hline No & 21 & 81.0 & \\
\hline Unknown & 2 & & \\
\hline Histological type of adenocarcinoma & & & 0.983 \\
\hline Well & 8 & 87.5 & \\
\hline Mod & 15 & 73.3 & \\
\hline Unknown & 3 & & \\
\hline
\end{tabular}

CEA: Carcinoembryonic antigen; SBRT: stereotactic body radiotherapy; CA19-9: carbohydrate antigen 19-9; GTV: gross tumor volume; BED: biologically effective dose; well: well differentiated adenocarcinoma; mod: moderately differentiated adenocarcinoma.

demonstrated approximately 80-90\% 5-year LC rates $(9,10)$. We also demonstrated favorable treatment outcomes with 1year LC of $96 \%$ in stage I lung cancer patients treated with Cyberknife $^{\circledR}$ (22). Several investigators have offered explanations for the relatively unfavorable LC as indicated by the presence of satellite tumor cells around the pulmonary lesion or the higher ratio of hypoxic tumor cells in the lesion (23-25). In our study, however, all local recurrences occurred within the radiation field, and we found no local recurrence caused by the satellite lesion.
Several investigators have suggested that patient age, preSBRT CEA, primary site (colon or rectum), number of pulmonary lesions, tumor size, radiation dose of SBRT, and adjuvant chemotherapy after SBRT were significant prognostic factors $(15,26,27)$. In the present study, tumor size was the only significant prognostic factor for LC, likely due to the small number of patients. In our study, patients with tumor size $\geq 10 \mathrm{~mm}$ had significantly poorer LC compared to those with tumor size $<10 \mathrm{~mm}$ (Table II).

Several authors have suggested that a very high dose of SBRT should be delivered to achieve favorable LC $(19,26-$ 28 ). Qiu et al. have reported that patients who received $\geq 80$ Gy 10 had better LC than those who received $<80 \mathrm{~Gy}_{10}$ (26). Jingu et al. have noted that patients who received $\geq 100 \mathrm{~Gy}_{10}$ to D95 of PTV had better LC than those who received $<100$ $\mathrm{Gy}_{10}$ (27). In the present study, Cyberknife ${ }^{\circledR}$ was used for the treatment, and very high doses were concentrated to the pulmonary tumors. Even though most patients received $>130$ $\mathrm{Gy}_{10}$ to D99 of CTV, the LC was relatively unfavorable.

One issue with the actual SBRT dose delivered to the small pulmonary lesion is that the accuracy of SBRT dose is influenced by the choice of treatment planning algorithm because of the use of small fields with its physical uncertainties and tissue inhomogeneity with high/low density interface (12). Even when the prescription dose is the same, the actual dose delivered to the tumor varies markedly, because there are various methods for determining isodose values. Furthermore, intrafractional movement of the pulmonary tumor causes uncertainty regarding the dose delivered to the tumor. Therefore, not only the optimal dose/fraction but also the optimal methods of prescription or isodose values, should be evaluated (19). Further study is required to define the optimal prescription dose for pulmonary oligometastasis from CRC.

None of the patients developed $\geq$ grade 2 toxicity from SBRT in the present study. Several investigators have also reported a low risk of pulmonary toxicity by SBRT (14-19). SBRT using CyberknifeR can minimize the dose to normal tissues, which results in a low incidence of pulmonary toxicity. However, treatment should be performed carefully, especially when the patient has poor cardiopulmonary function or concomitant disease such as interstitial pneumonitis or connective tissue disease.

Our study has several limitations. First, this was a singleinstitution retrospective study with a small number of patients. Second, patient background was heterogeneous. Third, median follow-up period after SBRT was short. Despite these limitations, given that the optimal treatment method of SBRT for pulmonary oligometastasis from CRC has not been thoroughly evaluated, and its indication has not been determined yet, our study offers useful information on the treatment of pulmonary oligometastasis from CRC. 
In conclusion, this study showed the efficacy and safety of SBRT in patients with pulmonary oligometastasis from CRC. Although very high doses were delivered to the tumors, the LC obtained in this study was not satisfactory when compared to that for stage I primary lung cancer or for pulmonary metastases from other cancers reported in the literature. The optimal dose and fractionation schedule for this disease remain controversial. Further prospective studies with larger cohorts are needed to determine the appropriate treatment for pulmonary oligometastasis from CRC.

\section{Conflicts of Interest}

The Authors have no conflicts of interest to declare in relation to this study.

\section{Authors' Contributions}

NK, SK, and SN contributed to the conception and design of the study. NK contributed to the collection and assembly of data. NK and TA contributed to the analysis and interpretation of data. YK, $\mathrm{RH}$, and $\mathrm{MI}$ contributed to physical quality assurance and quality control of SBRT. NK, TA, and SN contributed to the drafting of the article. TA, SS, and YR contributed to the critical revision of the article for important intellectual content. SK contributed to the final approval of the article. All Authors read and approved the version submitted for publication.

\section{References}

1 Ferlay J, Soerjomataram I, Dikshit R, Eser S, Mathers C, Rebelo M, Parkin DM, Forman D and Bray F: Cancer incidence and mortality worldwide: sources, methods and major patterns in GLOBOCAN 2012. Int J Cancer 136(5): E359-386, 2015. PMID: 25220842. DOI: $10.1002 /$ ijc. 29210

2 Edwards BK, Ward E, Kohler BA, Eheman C, Zauber AG, Anderson RN, Jemal A, Schymura MJ, Lansdorp-Vogelaar I, Seeff LC, van Ballegooijen M, Goede SL and Ries LA: Annual report to the nation on the status of cancer, 1975-2006, featuring colorectal cancer trends and impact of interventions (risk factors, screening, and treatment) to reduce future rates. Cancer 116(3): 544-573, 2010. PMID: 19998273. DOI: 10.1002/cncr.24760

3 Hashiguchi Y, Muro K, Saito Y, Ito Y, Ajioka Y, Hamaguchi T, Hasegawa K, Hotta K, Ishida H, Ishiguro M, Ishihara S, Kanemitsu Y, Kinugasa Y, Murofushi K, Nakajima TE, Oka S, Tanaka T, Taniguchi H, Tsuji A, Uehara K, Ueno H, Yamanaka T, Yamazaki K, Yoshida M, Yoshino T, Itabashi M, Sakamaki K, Sano K, Shimada Y, Tanaka S, Uetake H, Yamaguchi S, Yamaguchi N, Kobayashi H, Matsuda K, Kotake K and Sugihara K; Japanese Society for Cancer of the Colon and Rectum: Japanese Society for Cancer of the Colon and Rectum (JSCCR) guidelines 2019 for the treatment of colorectal cancer. Int J Clin Oncol 25(1): 1-42, 2020. PMID: 31203527. DOI: 10.1007/s10147-019-01485-Z

4 Niibe Y and Hayakawa K: Oligometastases and oligo-recurrence: The new era of cancer therapy. Jpn J Clin Oncol 40(2): 107-111, 2010. PMID: 20047860. DOI: 10.1093/jjco/hyp167

5 Alongi F, Arcangeli S, Filippi AR, Ricardi U and Scorsetti M: Review and uses of stereotactic body radiation therapy for oligometastases. Oncologist 17(8): 1100-1107, 2012. PMID: 22723509. DOI: 10.1634/theoncologist.2012-0092

6 National Comprehensive Cancer Network. NCCN Clinical Practice Guideline in Oncology (NCCN Guidelines ${ }^{\circledR}$ ) Colon Cancer. Available at: https://www.nccn.org/professionals/physician_gls/ pdf/colon.pdf [Last accessed March 9, 2020]

7 Navarria P, De Rose F and Ascolese AM: SBRT for lung oligometastases: Who is the perfect candidate? Rep Pract Oncol Radiother 20(6): 446-453, 2015. PMID: 26696785. DOI: 10.1016/j.rpor.2014.11.005

8 Amsbaugh MJ and Woo SY: Stereotactic Radiation Therapy Techniques. In: Principles \& Practice of Radiation Oncology $7^{\text {th }}$ edition. Halperin EC, Wazer DE, Perez CA, Brady WL (eds.). Alphen aan den Rijn, Wolters Kluwer, pp. 436-446, 2018.

9 Zheng X, Schipper M, Kidwell K, Lin J, Reddy R, Ren Y, Chang A, Lv F, Orringer M and Spring Kong FM: Survival outcome after stereotactic body radiation therapy and surgery for stage I non-small cell lung cancer: a meta-analysis. Int J Radiat Oncol Biol Phys 90(3): 603-611, 2014. PMID: 25052562. DOI: 10.1016/j.ijrobp.2014.05.055

10 Nagata Y and Kimura T: Stereotactic body radiotherapy (SBRT) for Stage I lung cancer. Jpn J Clin Oncol 48(5): 405-409, 2018. PMID: 29635536. DOI: 10.1093/jjco/hyy034

11 Wild AT and Yamada Y: Treatment options in oligometastatic disease: stereotactic body radiation therapy - focus on colorectal cancer. Visc Med 33(1): 54-61, 2017. PMID: 28612018. DOI: $10.1159 / 000454685$

12 Benedict SH, Yenice KM, Followill D, Galvin JM, Hinson W, Kavanagh B, Keall P, Lovelock M, Meeks S, Papiez L, Purdie T, Sadagopan R, Schell MC, Salter B, Schlesinger DJ, Shiu AS, Solberg T, Song DY, Stieber V, Timmerman R, Tomé WA, Verellen D, Wang L and Yin FF: Stereotactic body radiation therapy: The report of AAPM Task Group 101. Med Phys 37(8): 4078-4101, 2010. PMID: 20879569. DOI: 10.1118/1.3438081

13 Kimura T, Nagata Y, Harada H, Hayashi S, Matsuo Y, Takanaka T, Kokubo M, Takayama K, Onishi H, Hirakawa K, Shioyama $\mathrm{Y}$ and Ehara T: Phase I study of stereotactic body radiation therapy for centrally located stage IA non-small cell lung cancer (JROSG10-1). Int J Clin Oncol 22(5): 849-856, 2017. PMID: 28466183. DOI: 10.1007/s10147-017-1125-y

14 Kim MS, Yoo SY, Cho CK, Yoo HJ, Choi CW, Seo YS, Kang JK, Lee DH, Hwang DY, Moon SM, Kim MS, Kang HJ and Kim YH: Stereotactic body radiation therapy using three fractions for isolated lung recurrence from colorectal cancer. Oncology 76(3): 212-219, 2009. PMID: 19218825. DOI: 10.1159/000201932

15 Jung J, Song SY, Kim JH, Yu CS, Kim JC, Kim TW, Jeong SY, Kim SS and Choi EK: Clinical efficacy of stereotactic ablative radiotherapy for lung metastases arising from colorectal cancer. Radiat Oncol 10: 238, 2015. PMID: 26588896. DOI: 10.1186/ s13014-015-0546-x

16 Filippi AR, Badellino S, Ceccarelli M, Guarneri A, Franco P, Monagheddu C, Spadi R, Ragona R, Racca P and Ricardi U: Stereotactic ablative radiation therapy as first local therapy for lung oligometastases from colorectal cancer: a single-institution cohort study. Int J Radiat Oncol Biol Phys 91(3): 524-529, 2015. PMID: 25542308. DOI: 10.1016/j.jirobp.2014.10.046

17 Carvajal C, Navarro-Martin A, Cacicedo J, Ramos R and Guedea F: Stereotactic body radiotherapy for colorectal lung oligometastases: preliminary single-institution results. J BUON 20(1): 158-165, 2015. PMID: 25778311. 
18 Agolli L, Bracci S, Nicosia L, Valeriani M, De Sanctis V and Osti MF: Lung metastases treated with stereotactic ablative radiation therapy in oligometastatic colorectal cancer patients: outcomes and prognostic factors after long-term follow-up. Clin Colorectal Cancer 16(1): 58-64, 2017. PMID: 27522627. DOI: 10.1016/j.clcc.2016.07.004

19 Takeda A, Sanuki N, Tsurugai Y, Oku Y and Aoki Y: Stereotactic body radiotherapy for patients with oligometastases from colorectal cancer: Risk-Adapted dose prescription with a maximum dose of 83-100 Gy in five fractions. J Radiat Res 57(4): 400-405, 2016. PMID: 26983981. DOI: 10.1093/jrr/rrw029

20 Okumura S, Kondo H, Tsuboi M, Nakayama H, Asamura H, Tsuchiya R and Naruke T: Pulmonary resection for metastatic colorectal cancer: experiences with 159 patients. J Thorac Cardiovasc Surg 112(4): 867-874, 1996. PMID: 8873711. DOI: 10.1016/S0022-5223(96)70085-5

21 Okumura T, Boku N, Hishida T, Ohde Y, Sakao Y, Yoshiya K, Higashiyama M, Hyodo I, Mori K and Kondo H: Surgical outcome and prognostic stratification for pulmonary metastasis from colorectal cancer. Ann Thorac Surg 104(3): 979-987, 2017. PMID: 28577846. DOI: 10.1016/j.athoracsur.2017.03.021

22 Miyazawa K, Shikama N, Okazaki S, Igari M, Hirai R, Kumazaki Y, Kato S: Pulmonary toxicity after robotic radiosurgery system and linear accelerator based stereotactic body radiation therapy (SBRT) for lung tumors. Nippon Act. Radiol Annual meeting of The Japan Radiological Society abstracts: S227, 2017.

23 Aoki M, Hatayama Y, Kawaguchi H, Hirose K, Sato M, Akimoto H, Miura H, Ono S and Takai Y: Stereotactic body radiotherapy for lung metastases as oligo-recurrence: A single institutional study. J Radiat Res 57(1): 55-61, 2016. PMID: 26494115. DOI: $10.1093 /$ jrr/rrv063

24 Welter S, Theegarten D, Trarbach T, Maletzki F, Stamatis G and Tötsch M: Safety distance in the resection of colorectal lung metastases: a prospective evaluation of satellite tumor cells with immunohistochemistry. J Thorac Cardiovasc Surg 141(5): 12181222, 2011. PMID: 21163502. DOI: 10.1016/j.jtcvs.2010.08.089
25 van Laarhoven HW, Kaanders JH, Lok J, Peeters WJ, Rijken PF, Wiering B, Ruers TJ, Punt CJ, Heerschap A and van der Kogel AJ: Hypoxia in relation to vasculature and proliferation in liver metastases in patients with colorectal cancer. Int J Radiat Oncol Biol Phys 64(2): 473-482, 2006. PMID: 16242253. DOI: 10.1016/j.ijrobp.2005.07.982

26 Qiu H, Katz AW, Chowdhry AK, Usuki KY, Singh DP, Metcalfe S, Cheruvu P, Chen Y, Okunieff P and Milano MT: Stereotactic body radiotherapy for lung metastases from colorectal cancer. Am J Clin Oncol 41(1): 53-58, 2018. PMID: 26270442. DOI: 10.1097/COC.0000000000000220

27 Jingu K, Matsuo Y, Onishi H, Yamamoto T, Aoki M, Murakami Y, Yamashita H, Kakuhara H, Nemoto K, Sakayauchi T, Okamoto M, Niibe Y, Nagata Y and Ogawa K: Dose escalation improves outcome in stereotactic body radiotherapy for pulmonary oligometastases from colorectal cancer. Anticancer Res 37(5): 2709-2713, 2017. PMID: 28476849. DOI: 10.21873/anticanres.11621

28 Kobiela J, Spychalski P, Marvaso G, Ciardo D, Dell'Acqua V, Kraja F, Błażyńska-Spychalska A, Łachiński AJ, Surgo A, Glynne-Jones R and Jereczek-Fossa BA: Ablative stereotactic radiotherapy for oligometastatic colorectal cancer: Systematic review. Crit Rev Oncol Hematol 129: 91-101, 2018. PMID: 30097241. DOI: 10.1016/j.critrevonc.2018.06.005

Received June 222020

Revised July 8, 2020

Accepted July 9, 2020 